\title{
Short communication: Attempts to identify Clostridium botulinum toxin in milk from three experimentally intoxicated Holstein cows
}

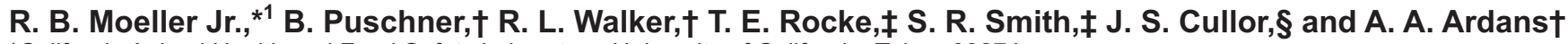 \\ ${ }^{*}$ California Animal Health and Food Safety Laboratory, University of California, Tulare 93274 \\ †California Animal Health and Food Safety Laboratory, University of California, Davis 95816 \\ fUS Geological Survey National Wildlife Health Center, Madison, WI 53711 \\ §Veterinary Medical Teaching and Research Center, University of California, Tulare 93274
}

\section{ABSTRACT}

Three adult lactating Holstein cows were injected in the subcutaneous abdominal vein with $175 \mathrm{ng} / \mathrm{kg}$ of body weight of Clostridium botulinum type C toxin (451 cow median toxic doses) to determine if this botulinum toxin crosses the blood-milk barrier. Whole blood (in sodium heparin) and clotted blood serum samples were taken at $0 \mathrm{~min}, 10 \mathrm{~min}$, and $3,6,9$, and $12 \mathrm{~h}$ postinoculation. Milk samples were taken at 0 min and at 3, 6, 9 and $12 \mathrm{~h}$ postinoculation. All samples were tested for the presence of the toxin using the mouse bioassay and immunostick ELISA test. The immunostick ELISA identified the toxin in whole blood and the mouse bioassay identified the toxin in serum at all times examined in all 3 animals. Toxin was not identified by either detection method in milk samples collected from the 3 animals. From these results, it appears that Clostridium botulinum type $\mathrm{C}$ toxin does not cross from the blood to the milk in detectable concentrations.

Key words: botulism, Clostridium botulinum toxin type $\mathrm{C}$, milk

Botulinum toxins are considered the most lethal biological toxic substances known to man. These toxins are known to cause paralysis and death in most mammals and birds. The neurotoxins are produced under anaerobic conditions by certain strains of Clostridium botulinum, Clostridium baratii, and Clostridium butyricum. Eight botulinum toxins have been identified on the basis of immunological characteristics and are designated as botulinum toxins type $\mathrm{A}, \mathrm{B}, \mathrm{C}_{1}, \mathrm{C}_{2}, \mathrm{D}$, E, F, and G (Hatheway, 1993; Cherington, 2004). Each of these toxins is produced by different strains of the bacteria that are usually found in different environmental matrices. In man, botulinum intoxication has been associated primarily with toxin types A, B, E, F, and

Received November 21, 2008.

Accepted January 2, 2009.

${ }^{1}$ Corresponding author: rbmoeller@ucdavis.edu
G. Cattle tend to become intoxicated with toxin types $\mathrm{B}, \mathrm{C}$, and D.

Outbreaks of botulinum intoxication have occurred worldwide over the past several years and have resulted in catastrophic cattle losses. In cattle, intoxication with type $\mathrm{C}$ toxin has been associated with the accidental feeding of carrion (bird, cat, or dog carcasses) in the ration (Galey et al., 2000; Myllykoski et al., 2009). The ingestion of spoiled or improperly fermented hay or silage (particularly oat, rye, and barley silage) is a common source of Clostridium botulinum type B toxin intoxication (Wilson et al., 1995; Yeruham et al., 2003; Kelch et al., 2004). Clostridium botulinum type D intoxication is common in phosphorus-deficient areas where the toxin-contaminated bones are ingested (Dobereiner et al., 1992; Martin, 2003). Visceral botulism has been associated with botulinum intoxication, but is thought to be a rare event in ruminants (Bohnel et al., 2005). Wound infections contaminated with $C$. botulinum have not been reported.

In cattle and other mammals, intoxication with botulinum toxin is thought to occur by ingestion of the preformed toxin or the colonization of the intestinal tract with the bacteria, which release the toxin in the intestinal lumen for intestinal absorption. The toxin is then absorbed through the intestinal tract and distributed to the nerves via the bloodstream (Coffield, 2003; Cherington, 2004; Simpson, 2004). Upon entering nerve cells, the toxin exerts its effect primarily at the neuromuscular junctions of skeletal muscle by preventing the release of acetylcholine. This results in weakness and paralysis in the affected animal. Each of the toxin serotypes affects a different area of the docking mechanisms responsible for the release of acetylcholine (Coffield, 2003; Cherington, 2004; Davletov et al., 2005). Death of intoxicated animals is usually due to paralysis of the diaphragmatic musculature leading to respiratory arrest.

There is concern that botulinum toxins can be transported from the bloodstream to the milk of intoxicated animals. This concern has lead to the withholding of 
milk at affected dairies from animals that demonstrate clinical signs of intoxication and from normal animals (Department for the Environment, Food, and Rural Affairs, 2005). This concern is due to the fact that many substances are known to cross the blood-milk barrier and contaminate milk. The purpose of this limited study was to determine the ability of C. botulinum type $\mathrm{C}$ toxin to cross the blood-milk barrier from the circulatory system to milk in the mammary glands in detectable concentrations.

Clostridium botulinum type $\mathrm{C}_{\text {complex }}$ toxin in sterile PBS (pH 7.0) was obtained from a commercial source. Type $\mathrm{C}_{\text {complex }}$ toxin (Metabiologics, Madison, WI) was used instead of type $\mathrm{C}_{1}$ toxin exclusively because in the natural setting the toxin is expressed with both components of the type $\mathrm{C}$ toxin present $\left(\mathrm{C}_{1}\right.$ and $\mathrm{C}_{2}$ toxins). The concentration of the botulinum toxin provided by the manufacturer allowed standardization of the toxin to $2.5 \times 10^{3} \mathrm{ng} / \mathrm{mL}$ in PBS. Aliquots of 6 $\mathrm{mL}$ containing $15.0 \times 10^{3} \mathrm{ng}$ of toxin were frozen at $-70^{\circ} \mathrm{C}$. After 2 wk at $-70^{\circ} \mathrm{C}$, an aliquot was thawed and the mouse lethal dose was determined to be $0.1 \mathrm{ng}$ using previously described methods (Hatheway, 1979). The toxin used in the experimental intoxications was maintained at $-70^{\circ} \mathrm{C}$ until used. The toxin was thawed immediately before administration and further diluted to the desired dose in sterile PBS.

Three adult, lactating, nonpregnant Holstein cows were used in this study. Each cow was given a thorough clinical examination upon arrival to ensure that the animal was in good health and did not have mastitis (by SCC). Animals were housed in a dirt lot with feed and water provided at all times. Body weight in kilograms was determined to calculate the amount of toxin to be administered by intravenous inoculation into the subcutaneous abdominal (milk) vein. The median toxic dose for milking adult Holstein dairy cows was previously determined to be $0.388 \mathrm{ng} / \mathrm{kg}$ of $\mathrm{BW}$ (Moeller et al., 2003). Each cow was administered a single dose of Clostridium botulinum type $\mathrm{C}$ toxin, $175 \mathrm{ng} / \mathrm{kg}$ of BW (1,750 mouse lethal doses $/ \mathrm{kg}$ ) or 451 lethal dose $50 \%\left(\mathbf{L D}_{50}\right)$ for cattle, to ensure that each milliliter of blood contained 20.5 mouse lethal doses present in the bloodstream at the time of initial blood sampling (A cow's blood volume is $8.52 \%$ of its BW (Schalm, 1975) or $85.2 \mathrm{~mL} / \mathrm{kg}$ of $\mathrm{BW} ; 1,750$ mouse lethal doses $/ \mathrm{kg}$ of BW divided by $85.2 \mathrm{~mL}$ of blood $/ \mathrm{kg}$ of BW yields 20.5 mouse lethal doses (2.05 ng of toxin/mL of blood).

Blood samples (whole blood in sodium heparin tubes and clotted blood) and milk were taken from each animal just before receiving the toxin. Blood samples were only collected $10 \mathrm{~min}$ postinjection (PI). Additional blood and milk samples were taken from each animal
$3,6,9$, and $12 \mathrm{~h}$ PI (if still alive) and at the time of euthanasia.

At each sampling, animals were examined for clinical signs of botulism such as constipation, decreased tail tone, ease of tongue extension and decrease in tongue retraction, decreased palpebral reflex, muscle weakness, muscle fasciculation, paresis, and paralysis. Once an animal was unable to rise, the animal was killed by captive bolt.

Whole blood (sodium heparin tubes), clotted blood samples, and milk samples were collected at the previously described times. The milk samples were placed in $40-\mathrm{mL}$ aliquots and frozen immediately at $-70^{\circ} \mathrm{C}$. Serum was separated by centrifugation, drawn off, and frozen immediately at $-70^{\circ} \mathrm{C}$. Whole blood and milk samples were refrigerated and shipped on wet ice to the US Geological Survey National Wildlife Health Center (Madison, WI), where these samples were tested for $C$. botulinum type $\mathrm{C}$ toxin using an immunostick ELISA test as described previously (Rocke et al., 1998). This test is an antigen-capture ELISA utilizing chicken IgY antitoxin as the primary antibody; $1.0-\mathrm{mL}$ aliquots of whole blood and milk are used for testing. The samples are incubated for $48 \mathrm{~h}$, washed, and immersed in secondary antibody followed by labeled conjugate and substrate. Toxin spiked and unspiked blood and milk samples served as positive and negative controls. Milk and serum samples were also evaluated for toxin by the mouse bioassay as described previously (Hatheway, 1979). The mouse bioassay is performed using a $0.5-\mathrm{mL}$ aliquot of milk or serum injected intraperitoneally into the mouse. The mice are observed for clinical signs of botulism (hourglass or wasp-waisted appearance with respiratory distress and progressive paralysis followed by death) for $5 \mathrm{~d}$. Control mice were given type $\mathrm{C}$ botulinum antitoxin as well as the test material to ensure they were protected from the toxin. The detection limit of $C$. botulinum type $\mathrm{C}$ toxin by the mouse bioassay is 1 mouse lethal dose $(0.1 \mathrm{ng}) / 0.5 \mathrm{~mL}$ for both serum and milk (R. L. Walker; personal communication). The detection limit of the toxin using the immunostick ELISA is $0.1 \mathrm{ng} / \mathrm{mL}$ in milk and $0.25 \mathrm{ng} / \mathrm{mL}$ in whole blood (T. E. Rocke, personal communication).

Animals were necropsied, and lung, liver, kidney, spleen, rumen, mammary gland, abomasum, ileum, spiral colon, brain, sciatic nerve, and biceps femoris muscle were collected from the killed animals for histopathological examination. Tissues were fixed in $10 \%$ neutral buffered formalin, sectioned at $7 \mu \mathrm{m}$, and stained with hematoxylin and eosin.

All animals were acquired, retained, and used in compliance with local, state, and federal regulations and laws. The experiments were conducted under the 
Table 1. Identification of botulism toxin Type C in whole blood, serum, and milk of animals A, B, and C

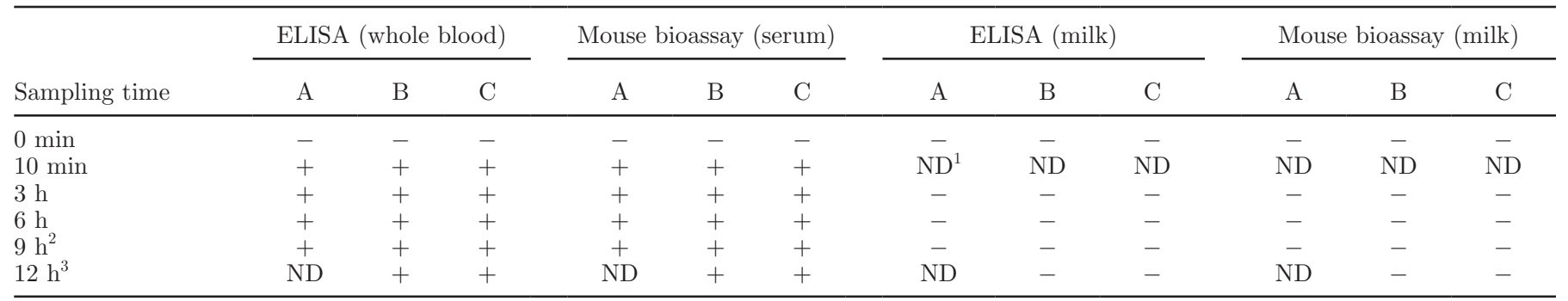

${ }^{1} \mathrm{ND}=$ not determined.

${ }^{2}$ Animal A killed at $9 \mathrm{~h}$.

${ }^{3}$ Animal B killed at $11.5 \mathrm{~h}$; animal $\mathrm{C}$ killed at $12 \mathrm{~h}$.

approval of the University of California Institutional Animal Care and Use Committee. Animals were monitored at all times during the experiment to avoid unnecessary discomfort. Once an animal could not stand or appeared to be in distress, the animal was euthanized.

Toxin detection for whole blood, serum, and milk samples is presented in Table 1. Clostridium botulinum type $\mathrm{C}$ toxin was detected in all serum and whole blood samples tested at $10 \mathrm{~min}$ and up to the time of euthanasia of the animal (animal $\mathrm{A}=9 \mathrm{~h}$; animal $\mathrm{B}=$ $11.5 \mathrm{~h}$; and animal $\mathrm{C}=12 \mathrm{~h}$ ). Milk samples from all 3 animals were also tested by the immunostick ELISA and mouse bioassay and were negative for the detection of toxin at all time points. Milk was not tested at 10 min because the animals had been milked at time 0 , so no milk was present at 10 min PI.

Clinically, all animals appeared normal at $3 \mathrm{~h}$ PI. Animal A demonstrated clinical signs of botulism at 6 h PI (restless on feet, muscle weakness, and decreased jaw, tongue, and tail tone). At $9 \mathrm{~h}$, the animal had severe muscle weakness and was unable to rise. The animal was alert but demonstrated markedly decreased tongue retraction capability and laxity in jaw and tail tone. The animal was killed at this time. Animal B appeared normal at 3 and $6 \mathrm{~h}$ PI. At $9 \mathrm{~h} \mathrm{PI}$, the animal was alert but restless on its feet. The animal also showed some slight muscle weakness and mild decrease in tongue retraction and laxity in jaw and tail tone. At $11.5 \mathrm{~h}$, the animal was down and unable to rise. At this time, the animal was killed. Animal C appeared normal at 3 and $6 \mathrm{~h}$ PI. At $9 \mathrm{~h} \mathrm{PI}$, the animal was alert but demonstrated muscle weakness and shifted its weight from leg to leg. The animal would lie down but was still able to get up. The tongue could be easily retracted and the jaw and tail tone was moderately lax. At 12 $\mathrm{h}$, the animal was unable to rise and had markedly decreased tongue retraction and jaw and tail tone laxity. The animal was killed at this time. Necropsy and histopathology on all 3 animals failed to identify any lesions that could be associated with botulism.
Based on the results of this limited study, it appears that type $\mathrm{C}$ botulinum toxin does not cross into milk from the blood of botulinum intoxicated cows at currently detectable levels $(0.1 \mathrm{ng} / 0.5 \mathrm{~mL}$ using the mouse bioassay and $0.1 \mathrm{ng} / \mathrm{mL}$ using the immunostick ELISA).

These results help support our belief that the toxin does not cross from the bloodstream into the milk. These results are similar to what was seen in milk samples tested by these 2 methods during the determination of the median toxic dose of type $\mathrm{C}$ botulinum toxin in Holstein cattle. In that study, very small concentrations of the toxin caused the animals to become intoxicated, yet no toxin was detected in the milk from these animals (Moeller et al., 2003).

It is unknown why detectable levels of $C$. botulinum type $\mathrm{C}$ toxin did not cross the blood-milk barrier in this experiment. It is possible that the animals died so quickly that the toxin did not have time to cross from the bloodstream into the milk. Although this may be a possibility it is also possible that the toxin does not have the ability to be transported to milk.

Many compounds cross quickly from the bloodstream and are incorporated into the milk (Wilson et al., 1980; Dorman et al., 2001). Entry into the mammary gland occurs either by passive diffusion or active transport from the vascular system. Factors affecting the entry of compounds from the blood into the mammary gland and milk include the molecular size, lipophilicity, protein receptor attachments for transport, and $\mathrm{pH}$ of the substance (Dorman et al., 2001). Mammary gland epithelial cells also form tight junctions that limit paracellular transport and restrict the movement of many agents (Dorman et al., 2001; Edwards et al., 2005). Therefore, many xenobiotics passively diffuse through the epithelial barrier or are actively transported through the epithelial cell usually attached to proteins (Edwards et al., 2005).

Little is known about the transport of botulinum toxin through the circulatory system. However, the 
ability of the toxin to be transported through the intercellular space to the nerves suggests that the toxin is either loosely bound to serum proteins or free in the serum. It is possible that the large size of the botulinum toxin $(150 \mathrm{kDa})$ limits penetration through the basement membrane of the gland and prevents the toxin from transport to the mammary gland lumen. It is also possible that the toxin is unable to attach to the cell membrane for active or passive transport thorough the mammary epithelium and into milk secretions.

The lipophilicity of botulinum toxin complex is also unknown. Because botulinum toxin is highly soluble in water, it is unlikely that it is attracted to lipophilic substances that could aid transport through the mammary gland epithelium and into the lumina of the gland. It is also possible that the mammary epithelium lacks the receptors for attachment and internalization of the toxin into the epithelial cells. This would make it difficult for the toxin to be actively secreted or transported into the milk.

Cow's milk has a pH of approximately 6.6 (Edwards et al., 2005). Milk is a weak acid compared with the neutral fluid plasma in the vascular system. A more basic compound with a higher pKa may be transported by active or passive mechanisms more easily into the milk than a compound that is more acidic and has a lower pKa. Thus, these physiological and chemical interactions may cause the botulinum toxin (a complex metalloprotease protein that is easily dissolved in water) to be poorly transported and concentrated in milk from the blood (Wilson et al., 1980; Dorman et al., 2001).

In a cow with mastitis, it is unclear if the transport of the toxin can occur. Damage to the ductal and glandular epithelium could possibly lead to vascular leakage and the movement of the toxin into the mammary ductal system. In a recent report, a cow that was intoxicated with $C$. botulinum type B toxin had the toxin detected in milk from only one mammary gland quarter that had mastitis (Bohnel et al., 2005). If an animal had systemic spread of the toxin and the toxin had the ability to be transported from the circulatory system across to the mammary gland, it would be assumed that the toxin would be identified in all quarters, not in only one quarter, as in this case. This suggests that the mastitisaffected gland allowed neurotoxin to be secreted into the milk. It is also possible that $C$. botulinum organisms may have been present in the infected mammary quarter causing release of toxin, which could be absorbed by the bloodstream leading to the intoxication of the animal (wound-type botulism). In this case, milk from the animal did not contain anaerobic bacteria. However, the animal had been treated with antibiotics and no bacterial cultures were performed on the quarters of the mammary gland so the origin of the toxin is unknown.

Based on the findings from the present study, it appears that injection and presumably ingestion of Clostridium botulinum type $\mathrm{C}$ toxin does not cross the blood-milk barrier in currently detectable quantities by the mouse bioassay or immunostick ELISA techniques. This supports our hypothesis that botulinum type C toxin does not cross into the mammary gland; however, as more sensitive procedures are developed, the detection of much smaller quantities of the toxin (i.e., less than picogram levels) in milk samples will be possible. Also, the other botulinum toxins are distinct toxins that need to be individually studied to completely conclude that none of these toxins will cross from the bloodstream into milk.

\section{REFERENCES}

Bohnel, H., B. Neufeld, and F. Gessler. 2005. Botulism neurotoxin type $\mathrm{B}$ in milk from a cow affected by visceral botulism. Vet. J. 169:124-125.

Cherington, M. 2004. Botulism: Update and review. Semin. Neurol. $24: 155-162$.

Coffield, J. A. 2003. Botulism neurotoxin: The neuromuscular junction revisited. Crit. Rev. Neurobiol. 15:175-195.

Davletov, B., M. Bajohrs, and T. Binz. 2005. Beyond BOTOX: Advantages and limitations of individual botulinum neurotoxins. Trends Neurosci. 28:446-452.

Department for the Environment, Food and Rural Affairs. 2005. Advisory committee on the microbiological safety of food ad hoc group on botulism in cattle. Report on botulism in cattle. http:// www.food.gov.uk.multimed/pdf/acmsf2006botulismcattle.pdf

Dobereiner, J., C. H. Tokarnia, J. Langenegger, and I. S. Dutra. 1992. Epizootic botulism of cattle in Brazil. Dtsch. Tierarztl. Wochenschr. 99:188-190.

Dorman, D. C., S. L. Allen, J. K. Byczkowski, L. Claudio, J. E. Fisher Jr., J. W. Fisher, G. J. Harry, A. A. Li, S. L. Makris, S. Padilla, L. G. Sultatos, and B. E. Mileson. 2001. Methods to identify and characterize developed neurotoxicity for human health risk assessment. III: Pharmacokinetic and pharmacodynamic considerations. Environ. Health Perspect. 109:101-111.

Edwards, J. E., J. Alcorn, J. Savolainen, B. D. Anderson, and P. J. McNamara. 2005. Role of P-glycoprotein in distribution of nelfinavir across the blood-mammary tissue barrier and blood brain barrier. Antimicrob. Agents Chemother. 49:1626-1628.

Galey, F. D., R. Terra, R. Walker, J. Adaska, M. A. Eichebarne, B. Puschner, E. Fisher, R. H. Whitlock, T. Rocke, D. Willoughby, and E. Tor. 2000. Type C botulism in dairy cattle from feed contaminated with a dead cat. J. Vet. Diagn. Invest. 2:204-209.

Hatheway, C. L. 1979. Laboratory procedures for cases of suspected infant botulism. Rev. Infect. Dis. 1:647-651.

Hatheway, C. L. 1993. Clostridium botulinum and other Clostridia that produce botulinum neurotoxin. Pages 3-16 in Clostridium botulinum, Ecology and Control in Foods. A. H. W. Housechild and K. L. Dodds, ed. Marcel Dekker Inc., New York, NY.

Kelch, W. J., L. A. Kerr, J. K. Pringle, B. W. Rohrbach, and R. H. Whitlock. 2004. Fatal Clostridium botulinum toxicosis in eleven Holstein cattle fed round bale barley haylage. J. Vet. Diagn. Invest. 12:453-455.

Martin, S. 2003. Clostridium botulinum type D intoxication a dairy herd. Can. Vet. J. 44:493-495.

Moeller, R. B., B. Puschner, R. L. Walker, T. Rocke, F. D. Galey, J. S. Cullor, and A. A. Ardans. 2003. Determining the median toxic dose of type $\mathrm{C}$ botulinum toxin in lactating dairy cows. J. Vet. Diagn. Invest. 15:523-526. 
Myllykoski, J., M. Lindstrom, R. Keto-Timonen, H. Soderholm, J. Jakala, H. Kallio, A. Sukura, and H. Korkeala. 2009. Type C bovine botulism outbreak due to carcass contaminated nonacidified silage. Epidemiol. Infect. 137:284-293.

Rocke, T., S. R. Smith, and S. W. Nashold. 1998. Preliminary evaluation of a simple in vitro test for the diagnosis of type $\mathrm{C}$ botulinum in wild birds. J. Wildl. Dis. 34:744-751.

Schalm, O. W. 1975. Blood volume and water balance. Page $4-5$ in Veterinary Hematology. 3rd ed. O. W. Schalm, N. C. Jain, and E. J. Carroll, ed. Lea and Febiger, Philadelphia, PA.

Simpson, L. L. 2004. Identification of the major steps in botulinum toxin interaction. Annu. Rev. Pharmacol. Toxicol. 44:167-193.
Wilson, J. T., R. D. Brown, and D. R. Cherek. 1980. Drug excretion in human breast milk: Principles, pharmacokinetics and projected consequences. Clin. Pharmacokinet. 5:1-66.

Wilson, R. B., M. T. Boley, and B. B. Corwin. 1995. Presumptive botulism in cattle associated with plastic packaged hay. J. Vet. Diagn. Invest. 7:167-169.

Yeruham, I., D. Elad, Y. Avidar, K. Grinberg, D. Tiomkin, and M Monbaz. 2003. Outbreak of botulism type B in a dairy cattle herd: Clinical and epidemiological aspects. Vet. Rec. 153:270-272. 